\title{
ГРАКХАНСКИЙ ПРОЕКТ ПО ВОССТАНОВЛЕНИЮ КОРИНФА
}

\section{GRACCHAN PROJECT FOR THE RESTORATION OF CORINTH}

E. Lyahin

Summary: The article is devoted to the movement of the Gracchi brothers and the plans of the colonization of Greece, or rather the restoration of Corinth, which was destroyed by Roman troops under the leadership of Lucius Mummiy Achaean League in $146 \mathrm{BC}$, the Problem of destruction of defenseless cities of the Achaean Union, the imposition of the curse, became the movement of the Gracchi the symbol of the old victories of optimats. The project is the Foundation of a Roman colony on the territory of Corinth, which will already be carried out centurization, but the project itself will be canceled for political reasons. Will resume only at the very end of the dictatorship of Gaius Julius Caesar, in 44 BC.

The purpose of the study is to reveal the facts of the founding of the Roman colony in Corinth by the brothers Gracchi. The scientific novelty of the research lies in the fact that the article connects facts that were not previously considered in a general way. This is the fact of the struggle of the Gracchus against the optimates and the commercial and financial circles in Rome, who received super profits from the exploitation of the eastern provinces, through Fr. Delos and Athens. As a result, those actions of the Gracchans, which were associated with the founding of the Roman colony in Corinth, led to the creation of the project and centurization, but were sharply curtailed after the death of the Gracchi brothers and their associates. The article aims to describe the real reason for trying to found a Roman colony.

Keywords: Gracchan movement, Roman Corinth, centuriation, Lucius Mummius of Achaea.

\author{
Ляхин Евгений Владиславович \\ соискатель, ФБОУ ВО «Казанский Федеральный \\ университет»; Преподаватель, ФКОУВО «Пермский \\ институm ФСИН России» \\ Evgeny102@yandex.ru
}

Аннотация: Статья посвящена движению братьев Гракхов и планам колонизации Греции, а точнее восстановлению Коринфа, который был разрушен римскими войсками под руководством Луция Муммия Ахейского в 146 г. до н. э. Проблема разрушения беззащитного города Ахейского союза, наложение проклятия, стали для движения Гракхов символом старых побед оптиматов. Проект основания римской колонии на территории Коринфа, которой уже будет проведена центуриация, но сам проект будет отменен по политическим причинам. Возобновится только в самом конце диктатуры Гая Юлия Цезаря, в 44 г. до н. э.

Цель исследования - раскрыть факты основания римской колонии в Коринфе, братьями Гракхами. Научная новизна исследования в том, что в статье связываются факты, ранее не рассматривающиеся в общем ключе. Это факт борьбы Гракхов против оптиматов и торгово-финансовых кругов в Риме, которые получили сверхдоходы с эксплуатации восточных провинций, через 0. Делос и Афины. В результате, те действия гракханцев, которые были связаны с основанием римской колонии в Коринфе, привели к созданию проекта и центуриации, но были резко свернуты после гибели братьев Гракхов и их сподвижников. Статья призвана описать реальную причину попытки основать римскую колонию.

Ключевые слова: гракханское движение, римский Коринф, центуриация, Луций Муммий Ахейский.

блики год, а именно в 146 г. до н. э.

Как известно, разрушенный в результате Ахейской войны (147-145 гг. до н. э.) Коринф, был в глазах римлян оплотом последней надежды греков на независимость и былую гордость и славу Эллады. Поэтому консул Луций Муммий разрушает фактически сдавшийся город и покинутый руководством Ахейской федерации город (Paus. VII, 15; Polyb. XXXIX, 13; Vell. I. 13, 1; Justin. XXXIV. 2, 6; Eutr. XIV, 1-3). Причин для такой жестокости, а если учесть, что Коринф был крупным морским портом, который физически пришлось разрушать римской армии всю осень 146 г. до н. э. было несколько. Первая причина, это удовлетворение своих личных амбиций консула- Луция Муммия, который получил после разгрома Коринфа множество преференций - триумф, cognomen - «Ахейский». Сами Муммии были плебейским родом и входили в так называемый плебейский нобилитет и все победы Луция Муммия и акции в Греции, такие как разгром 
Ахейского союза, разрушение Коринфа, а также работа сенаторской комиссии, где, если обратить внимание входили исключительно люди Муммия (Paus. VII. 16, 5; Zon. IX, 31; Cic. add. Att. XIII. 6, 4; Polyb. XXXIX, 12). Все эти действия привели его партию к победе в сенате и в дальнейшем потеснили власть клана Метеллов, но ненадолго. Со смертью самого Луция Муммия род уходит на второй план. Вторая причина имела политическиемотивы, римляне фактически не за что, разрушая крупный мегаполис, устрашали и усмиряли остальные греческие города будущей римской власти, то есть облегчили работу второй сенаторской комиссии в Греции [6, с. 7]. Третья причина, Коринф в глазах Рима был символом воинственности Ахейского союза, который ахейцы, собственно, и защищали. Коринф, таким образом, понес всю вину за всех ахейцев. Таким образом, руины города были символом смирения Греции и победы Рима, но для популяров это был ещё и памятник победы оптиматов, в котором Муммий вошёл в пантеон героев, как и Сципионза разрушение Карфагена (Verg. Aen. VI, 836).

После 146 г. до н. э. Рим остался без крупных противников в Средиземноморском бассейне. Именно в этом Римская республика входит в эпоху так называемых гражданских войн. Движение Гракхов было ответом на начало экономических и социальных проблем внутри самой республики. После завоевания Италии, в Рим стали поступать в огромных количествах, военная добыча, дань и налоги с провинций. В Риме появляется прослойка сверхбогатых людей - олигархия, основной доход которых получают от крупных поместий. С другой стороны, после постоянных войн Рим наполнился множеством нищих людей и бродяг. Провинции после постоянных нашествий пришли в упадок, сказывалось отсутствие торговли и деловой активности, активизировались пираты. Так, например, Греция и Африка, будущие провинция Ахайя и Проконсульская Африка, вообще выключены из коммерческой деятельности и средиземноморской торговли, только Цезарь-диктатор благодаря 80.000 колонистам (Suet. lul. 42), восстановил их традиционное значение [1, с.35]. Усиливаются все виды противоречий внутри римского общества: противоречие между знатью и народом, знатью и деловыми кругами, патрициатом и нобилитетом, римлянами и союзниками, римлянами и провинциалами. Такого системного кризиса в римской республике не было никогда.

Гракхи и их сторонники откликнулись на этот глубоко системный кризис. Гракханские реформы были первой серьезной попыткой выйти из системного кризиса. Передел земли особенно ager publicus, введение земельного максимума для римских семей в 500 югеров. Это база аграрной реформы, после которой Гракхи продолжают своих изменения в социальной, экономической и политической сферах. Один из методов решения земельного вопроса, это основание колоний и вывод наиболее бед- ной прослойки населения из Рима, сначала в италийские города, а затем в Африку и Грецию.

О причинах вывода колонии в Африку на место бывшего Карфагена (колония Юнония) [2. с. 205], сказано уже достаточно много. Благодаря обилию нарративных источников, а также из так называемого аграрного закона народного трибуна Спурия Тория (111 г. до н. э.) (CIL. I, 200; 585). Наоборот, об основании колонии на месте Коринфа мы знаем очень мало. Часто в историографии говорится вскользь или не говориться вовсе. Но в законе Тория есть целый раздел «О коринфской колонии» строчки 96-105, но в самом конце надписи и она очень сильно повреждена.

Каковы же причины колониальной экспансии в Грецию. Ответить на такой вопрос можно несколько с помощью решения земельного вопроса нельзя, так, как всем известно, как мало в Греции пахотной земли и какого она качества, тем более что сам Коринф, это морской порт, а не аграрный полис. Во-вторых, часть хоры Коринфа была отдана Сикиону. И последнее Коринфика была предана проклятию. Чего же хотели Гракхи и их сторонники?

В 133 г. до н. э. во время выхода аграрного закона Тиберия Гракха (Lex Simpronia agraria) умирает царь Пергама, Аттал III (138-133 гг. до н. э.), и завещает своё царство Риму. Пергамское царство, римляне, правда, не сразу, из-за больших размеров превратили в римскую провинцию Азия (в 126 г. до н. э.). Появилась римская территория далеко на востоке, гдесвязь между ними осуществляется в основном по морю, где господствуют пираты. Чтобы защитить свои интересы, а также стимулировать коммерческую и деловую активность в провинциях, Гай Гракх начинает активную колонизационную политику в Римские республики.

В новом основании Коринфа, как римской колонии были достаточно консервативные экономические взгляды, а также своеобразной политической провокацией, руководствовались Гракхи и их последователи [1, с. 15]. Это доказывает, несколько фактов. Во-первых, Коринф лежал, как известно в наиболее узком месте полуострова Пелопоннес, гарантировавший безопасное плавание из Адриатики в Эгейское море и наоборот, то есть был своеобразным «мостом в Азию». Географически Коринф располагался посреди Истма и содердал две гавани, которые располагались в разных сторонах перешейка - Лехайон и Кенхереи. Цитадель Коринфа - Акрокоринф лежала на 573 м над уровнем моря. Лехайон порт Коринфа, находившийся в Коринфском заливе, осуществлял связь с Италией через Адриатическое море. Кенхереи - порт Коринфа, принимавший корабли Восточного Средиземноморья с Эгейского моря [1, с.65]. Коринф был центром коммерции уже в VIII в. до н. э. 
К тому же Коринф был местом триумфа оптиматов, снятие проклятия, основание города, было с религиозной точки святотатство, а нанёс бы своеобразную пощечину сенату Рима, который держался своих традиций. Таковы были основные мотивы для вывода колонии в Коринф, отметим, что до этого вывод колоний вне Италии не предпринимался.

Ещё одной причиной основания Коринфа, является настойчивое лоббирование самим Гаем Гракхом интересов всадничества. Причина такого лобби заключается в поиске более широкой базы поддержки самого гракхинского движения. И в рамках этого лоббирования, в 126 г. до н. э. Гай Гракх проводит законопроект «lex de prov. Asia a censoribus locanda». Для осуществления своих планов Гракх решил привлечь на свою сторону всадников, через сдачу на откуп провинций, то есть продажа права сбора налогов в провинции Азия на один год. Откуп провинции по новому закону осуществлялся прямо в Риме, а не в провинции как это было раньше (lex de provinciis consularibus). Фактически провинция Азия была отдана Гракхом на разграбление. Также Гай объявил провинции - «собственностью римского народа», что сделало его популярным, а всадники после этого закона стали самыми ярыми сторонниками Гая Гракха [3, с. 218-219]. Последний, таким образом, получил сразу два козыря в дальнейшей своей деятельности, он получил столь необходимые средства для реформ и основания колоний и поддержку всадничества. Коринф в данном случае, должен был стать центром деловой активности всего региона. Отметим, что таким центром должна была стать римская колония, а не греческий или малоазийский город, как это было в Афинах или на Делосе, где например был так называемый «латинский квартал» [5].

Дата создания проекта нам неизвестна, но известно две даты, от которых следует оттолкнутся. Первая дата - 122 г. до н. э. согласно Lex Rubria, выведена колония Юнония. Напомним, что закон Рубрия юридически связан с Lex Sempronia agraria (133 г. до н. э.), то есть вывод колоний за пределы Италии, входило ещё в планы Тиберия Гракха [4, с.200]. Вторая дата, от которой необходимо оттолкнуться это 111 г. до н. э., так называемый закон Тория, где четко упоминается о будущей центуриации Коринфской колонии, о том, какие земли будут входить в состав новой колонии, какие относиться к Сикиону. Таким образом, проект основания Коринфа был создан Гракхами или пост-Гракхами, была уже подготовлена центуриация земель, но после падения Гракхов и их сторонников проект был свернут, и римская колония в Коринфе так и осталась на бумаге, в отличие, например, от колонии Юнонии. Куда были посланы колонисты, и поселение получило официальный статус - римская колония. Продержись Гракхи дольше, то корабли с колонистами выехали бы и в новый Коринф.
Археологические данные [10, с.88] подтверждают тот факт, что поселение в Коринфе, точнее в северной части бывшего греческого города существовало скорее всего после упомянутого закона Тория 111 г. до н. э. Между участками была проложена дорога для двухколесной телеги. Земли Коринфа, переданные в фонд государственных земель Рима, подверглись центуриации, то есть были поделены на участки для продажи и установлены пограничные камни. То есть из ager publicus земли бывшего Коринфа, были переведены таким образом в статус частных земель для продажи (vectigalis as ager publicus). И многие из этих участков с пограничными камнями видел Цицерон в 63 г. до н. э. во время своего путешествия по Греции (Leg. agr. I, 5; II. 5, 1), и поселок на руинах бывшего греческого Коринфа (Tusc. III. 22, 5).

Таким образом, римское поселение в Коринфе, было необходимо и римлянам, и грекам, так как уходило в прошлое старое идеологическое, можно даже сказать, скорее аристократическое отношение к поверженным врагам с их осквернениями и проклятиями земель. Коринф, как морской порт был нужен прежде всего самим римлянам. Как перевалочная база для соединения Италии и восточных провинций, как надежный форпост, населенный римскими колонистами. Идеологически восстановленный Коринф символизировал победу популяров над оптиматами, а также означал разворот экономики Римского государства в сторону более прибыльной и доходной торговли, которая могла решить множество внутренних противоречий самой республики. Немало важное разворот Рима к провинциям, а точнее отказ от старой системы ограбления провинций и переход к налаживанию сотрудничества государства и его территорий. Также не следует забывать, что колонисты, прибывшие из Рима и Италии, освобождали земли, позволяя Гракхам более успешно проводить земельные реформы. Новый римский Коринф делал ближе провинцию Азия и особенно это было нужно всадникам-публиканам, которые выкачивали с помощью откупа огромные средства из бывшего Пергамского царства. Но, этот шаг как покажет исторический процесс завершиться в эпоху решительных действий Цезаря-диктатора (49-44 гг. до н э.). Следует обратить внимание на следующий факт. Колонисты, посланные Цезарем в Коринф прибыли не на пустырь, уставленный руинами и старым проклятием, а имеющий правильную центуриацию и уже со снятым проклятием территорией.

Стоит только вдохновляться действиями братьев Гракхов и их сторонников, которые помимо старой аристократии, державшийся своих традиций и старых побед, бросили вызов религии, традициям и морали древнеримского общества, которое всегда держалось ультраконсервативных устоев. Всё это закончит только через семьдесят лет Гай Юлий Цезарь, и старая полисная структура Рима уступит новому государственному орга- 
низму, как империя.

Таким образом, Гракханский проект восстановления Коринфа, не привлекавший до сих пор исследователей, ведет к следующим важным выводам. Движение братьев Гракхов открывает новую страницу истории Древнего Рима. Во-первых, римский Коринф, как мы увидим позднее надежно свяжет восток и запад Римского государства. Во-вторых, изменит систему отношений провинция и Рим. В-третьих, проект римского Коринфа изменит отношение самих римлян к бывшим врагам и проклятиям, в угоду получения прибыли от коммерции и торговли. Сотрудничество заменяет традиции «право сильного». В-четвертых, исходя из третьего пункта Рим вступает в свет капиталистических отношений, где на первые место выходит получение дохода законным путем, а не путем ограблений и контрибуций. Хотя последнее будет работать в Римском государстве до его конца.

1. Егоров А.Б., 2017: Рим: от республики к империи. СПб.

ЛИТЕРАТУРА

2. иирюшов Д.А., 2008: Аграрная политика Гая Гракха // Мнемон. Исследования и публикации по истории античного мира. СПб., 7. С. 203-211.

3. Лапыренок Р.В., 2016: Наследие аграрного закона Тиберия Гракха: земельный вопрос и политическая борьба в Риме 20-х гг. II в. до н. э., 298 с.

4. Лапыренок Р.В., Сморчков, А. М., 2014: Аппиан и пост-гракханское аграрное законодательство // Antiquitas Aeterna. 4. Нижний Новгород, С. $189-212$.

5. Хабихт Х., 1999: Афины: история эллинистического города. М.

6. Davies S., 2010. Carthage and Corinth, \& 146 BCE: Shifting Paradigms of Roman Imperium // Beyond Borders: Selected Proceedings of the Ancient Borderlands International Graduate Student Conference. Austin, P. 76-102.

7. Dinsmoor W.B. The Archons of Athens. Cambridge, 1993.

8. Nottmeyer H., 1995: Polybios und das Ende des Achaierbundes: Untersuchungen zu den römisch-achaiischen Beziehungen, ausgehend von der Mission des Kallikrates bis zur Zerstörung Korinths. München. 302 ss.

9. Purcell N., 1995: The sacking of Carthage and Corinth // Ethical and rhetoric classical essays for Donald Russel in his seventy-fifty birthday. 0xford, P. $229-241$.

10. Romano D.G., 2000: A tale of two cities: Roman colonies at Corinth // Romanization and the city. Creation, transformations and failures. Portsmouth, Rhode Island. P. 86-102.

11. Romano D.G., 2006: Roman surveyors in Corinth // American Philosophical society. 150. 1. P. 61-81.

(с) Ляхин Евгений Владиславович (Evgeny102@yandex.ru).

Журнал «Современная наука: актуальные проблемы теории и практики»

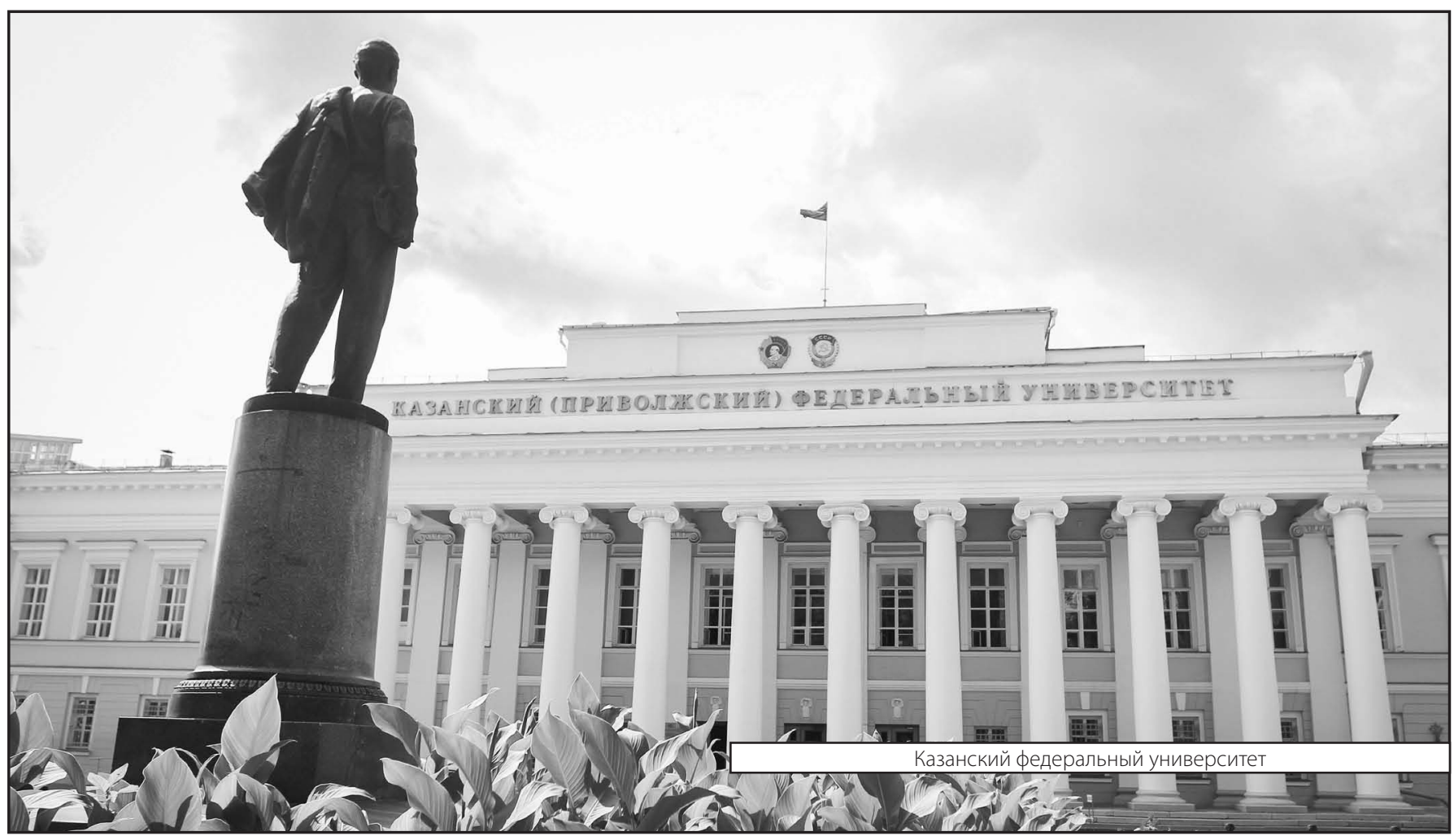

